\title{
Enhanced Magnetization of Sol-Gel Synthesized Pb-Doped Strontium Hexaferrites Nanocrystallites at Low Temperature
}

\author{
Shahid M. Ramay, ${ }^{1}$ Shahid Atiq, ${ }^{2}$ Murtaza Saleem, ${ }^{3}$ \\ Asif Mahmood, ${ }^{4}$ Saadat A. Siddiqi, ${ }^{5}$ Shahzad Naseem, ${ }^{2}$ Yousef Al-Zeghayer, ${ }^{4,6}$ \\ Nasser S. Alzayed, ${ }^{1}$ and Mohammed Shahabuddin ${ }^{1}$ \\ ${ }^{1}$ Department of Physics and Astronomy, College of Science, King Saud University, P.O. Box 800, Riyadh 11421, Saudi Arabia \\ ${ }^{2}$ Centre of Excellence in Solid State Physics, University of the Punjab, Lahore 54590, Pakistan \\ ${ }^{3}$ Department of Physics, School of Science and Engineering (SSE), Lahore University of Management Sciences (LUMS), \\ Lahore 54792, Pakistan \\ ${ }^{4}$ Department of Chemical Engineering, College of Engineering, King Saud University, P.O. Box 800, Riyadh 11421, Saudi Arabia \\ ${ }^{5}$ Interdisciplinary Research Centre in Biomedical Materials (IRCBM), COMSATS Institute of Information Technology, Defence Road, \\ Off Raiwind Road, Lahore 54600, Pakistan \\ ${ }^{6}$ Industrial Catalysts Research Chair, King Saud University, Riyadh 11421, Saudi Arabia \\ Correspondence should be addressed to Shahid Atiq; satiq.cssp@pu.edu.pk
}

Received 24 January 2014; Revised 1 May 2014; Accepted 3 May 2014; Published 27 May 2014

Academic Editor: Debasis Dhak

Copyright (C) 2014 Shahid M. Ramay et al. This is an open access article distributed under the Creative Commons Attribution License, which permits unrestricted use, distribution, and reproduction in any medium, provided the original work is properly cited.

Effect of $\mathrm{Pb}$ doping on the structural and low temperature magnetic properties of $\operatorname{SrPb}_{x} \mathrm{Fe}_{12-x} \mathrm{O}_{19}(x=0,0.1,0.2,0.3$, and 0.4$)$, synthesized by sol-gel autocombustion technique, has been investigated. The powder samples were sintered at $800^{\circ} \mathrm{C}$ for $2 \mathrm{~h}$ in order to develop the stable hexagonal phase, characteristic of the $\mathrm{SrFe}_{12} \mathrm{O}_{19}$ structure. The consequences of $\mathrm{Pb}$ substitution (at iron sites) on various structural parameters like lattice constants, unit cell volume, crystallite size, and porosity have been discussed. Fourier transform infrared frequency bands were utilized to determine the formation of tetrahedral and octahedral clusters of M-type ferrites. Hexagonal texture of the grains, a characteristic of the hexagonal crystal structure of $\mathrm{SrFe}_{12} \mathrm{O}_{19}$, was refined by $\mathrm{Pb}$ substitution. The magnetic properties, determined using a vibrating sample magnetometer, revealed that saturation magnetization decreased, while coercivity was increased with the increase of $\mathrm{Pb}$ contents. However, the increased squareness ratio and hence the energy product motivate the utilization of these ferrite compositions where hard magnetic characteristics are required. The increased values of saturation magnetization were observed at reduced temperature of $200 \mathrm{~K}$, attributable to the better spin alignments of individual magnetic moments at low temperature.

\section{Introduction}

M-type hexagonal ferrites belong to immensely valuable class of magnetic materials, with a host of applications ranging from simple permanent magnets used in electric motors to modern day applications, for instance, as radar wave absorbing materials. Owing to its high values of saturation magnetization and coercivity [1], strontium hexaferrite, in particular, is a very important member of this class of magnetic materials, being widely used in telecommunication [2], magnetooptic recording media, microwave devices [3], and electronic industry [4]. Various preparation techniques like coprecipitation process, molten salt method, solid state reaction method [5], double sintering ceramic technique [6], microwave-induced combustion process, sol-gel based synthesis routes [7], and so forth have been adopted by the researchers to refine the astonishing structural and magnetic properties of these ferrites. However, sol-gel based autocombustion route, being easier, energy efficient, and cheaper, has emerged as a novel technique to prepare single phase strontium hexaferrites. The crystal structure of $\mathrm{SrFe}_{12} \mathrm{O}_{19}$ is hexagonal which has a great influence on valuable characteristics of these ferrites. One-unit cell of these ferrites is composed of 64 ions that are distributed in such a way that 
these form two formula units, each having one spinel S-block and one hexagonal R-block [2]. The $\mathrm{Fe}^{3+}$ ions are oriented on five different crystallographic sites in the unit cell. These ions are the major cause of magnetism in these ferrites, resulting in net magnetic moment of $20 \mu_{\mathrm{B}}$ per formula unit $[8,9]$.

Ferrimagnetic strontium hexaferrites are n-type semiconductor with band gap energy of $0.6 \mathrm{eV}$. Researchers are attempting to improve the intrinsic properties of these ferrites for innovations. For this purpose, introduction of some divalent or trivalent dopant element and optimization of preparation technique play a vital role. Diamagnetic $\mathrm{Pb}$ ions, substituted at $\mathrm{Fe}$ sites with spin up, could enhance the hard magnetic characteristics of $\mathrm{SrFe}_{12} \mathrm{O}_{19}$ when doped stoichiometrically. Hence, it has been understood as a quite suitable dopant choice for these ferrites to improve not only the structural properties but also the magnetic properties $[2,3,8]$. In the present work, we have successfully employed sol-gel based autocombustion technique to prepare the ferrite samples in phase-pure form to investigate the structural and low temperature magnetic properties of $\mathrm{Pb}$-doped strontium hexaferrites for use in devices that work efficiently with high values of coercivity and electrical devices that show minimum energy losses at higher applied frequencies.

\section{Experimental}

Single phase polycrystalline samples with compositions $\mathrm{SrPb}_{x} \mathrm{Fe}_{12-x} \mathrm{O}_{19}(x=0.0,0.1,0.2,0.3$, and 0.4$)$ were prepared by a novel sol-gel based autocombustion route. A transparent homogenous solution was obtained by dissolving stoichiometric proportions of analytical grade strontium nitrate (Sigma Aldrich), iron (III) nitrate (Sigma Aldrich), lead (II) nitrate (Sigma Aldrich), and citric acid (Avonchem, UK) in $50 \mathrm{~mL}$ of deionized water. The relative molar concentrations of citric acid, used as a fuel, and metal nitrates were in the ratio of $2: 1$. The solution was placed over a hot plate, positioned in a fume hood. The temperature of the hot plate was gradually increased to $90^{\circ} \mathrm{C}$. The solution was continuously stirred using a magnetic stirrer at $500 \mathrm{rpm}$, for about $1 \mathrm{~h}$, until it converted into a soft gel. At that instance, the rotator was stopped and the stirrer was removed from the gel. The temperature of the gel was increased in steps up to $300^{\circ} \mathrm{C}$. As the gel was heated at this temperature for about $15 \mathrm{~min}$., it burnt suddenly and vigorously and converted into soft and fluffy powder. The product was grinded to get homogenously mixed powder samples. All the samples were synthesized using the same procedure and sintered at $800^{\circ} \mathrm{C}$ for $2 \mathrm{~h}$ in order to get hexagonal ferrite phases. Xray diffraction (XRD) was used to investigate the crystal structure of the prepared samples. The thermogravimetric/differential (TG/DTA) analysis was performed using EXSTAR SII TG/DTA 7300 analyzer in order to investigate any weight loss of the samples at high temperatures. The powder samples were then pelletized and surface morphology was analyzed using a JSM-6610 Oxford (with EDX attachment) scanning electron microscope (SEM). Energy dispersive Xray spectroscopy (EDX) was performed to get quantitative analysis of the samples. The formation of chemical bonds in

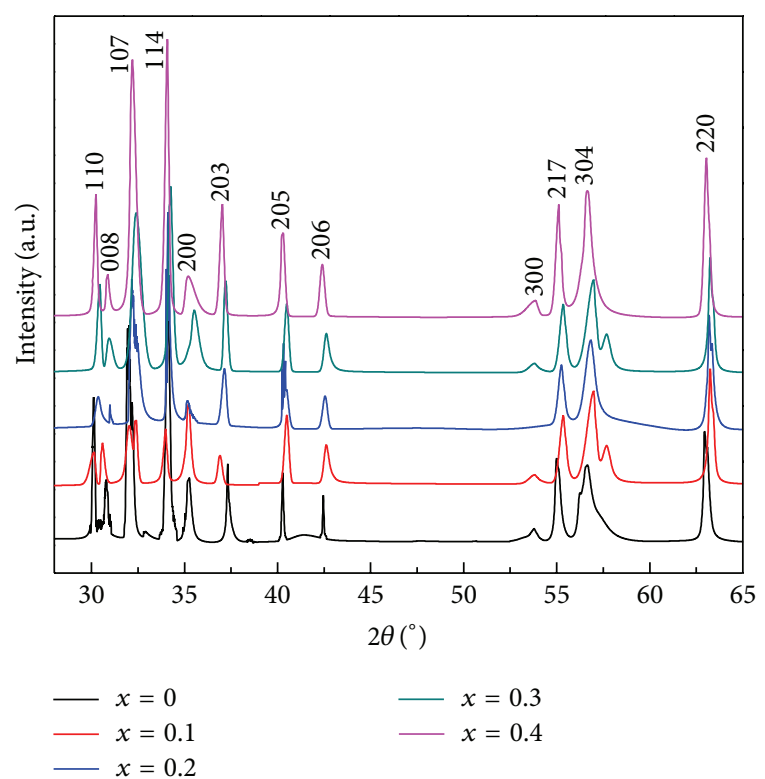

Figure 1: X-ray diffraction patterns of $\mathrm{SrPb}_{x} \mathrm{Fe}_{12-x} \mathrm{O}_{19}(x=0.0,0.1$, $0.2,0.3$, and 0.4 ) sample.

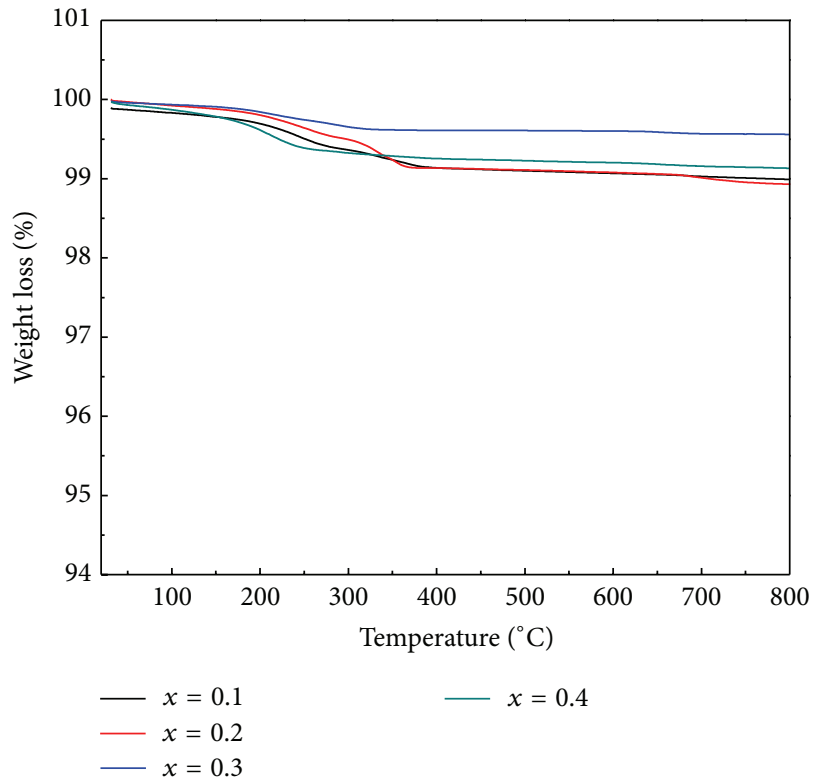

Figure 2: TGA spectra of $\mathrm{SrPb}_{x} \mathrm{Fe}_{12-x} \mathrm{O}_{19}(x=0.1,0.2,0.3$, and 0.4$)$ samples.

the desired crystal phase was confirmed by Fourier transform infrared spectroscopy (FTIR). Magnetic behavior of the samples was analyzed using a 14 Tesla Quantum design PPMS (Physical Properties Measurement System).

\section{Results and Discussion}

Crystal structure of all the prepared samples was determined by X-ray diffraction, following the complete procedure as 


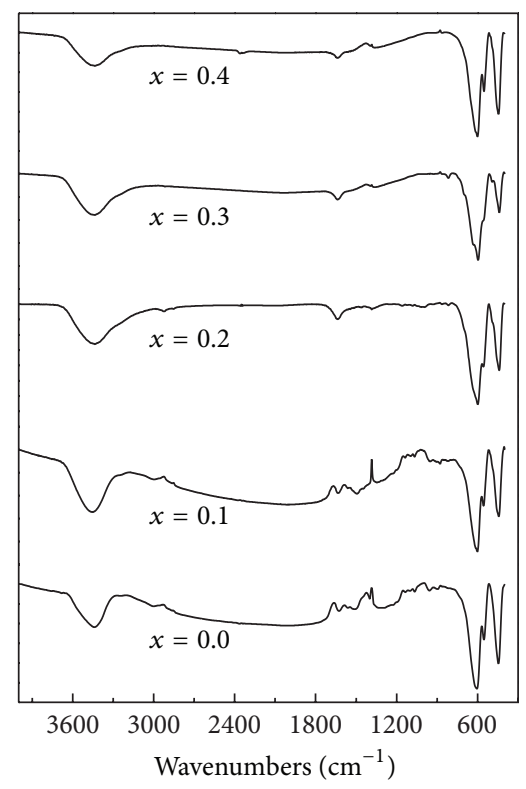

FIGURE 3: FTIR spectra of $\mathrm{SrPb}_{x} \mathrm{Fe}_{12-x} \mathrm{O}_{19}(x=0.0,0.1,0.2,0.3$, and 0.4) samples.

described by Cullity [10]. Data obtained from the diffractometer was plotted. Positions of the diffracted intensities were noted and corresponding values of $\sin ^{2} \theta$ were evaluated. These values were multiplied by $1 / 3,1 / 4$, and $1 / 7$ in order to find a repeated number named " $A$ " related to the lattice parameter " $a$ " and wavelength $(\lambda)$ of the incident radiation by the relation $A=\lambda^{2} / 3 a^{2}$. Using this relation, value of " $a$ " was evaluated for 200 plane. The relation $\sin ^{2} \theta-$ $A\left(h^{2}+h k+k^{2}\right)=C l^{2}$ was used to find a parameter, " $C$ " and hence the lattice constant, " $c$," using the expression $C=\lambda^{2} / 4 c^{2} . h k l$ values corresponding to all the diffracted intensities were determined and the patterns were indexed as shown in Figure 1. The indexing of the patterns revealed that crystal structures of all the samples exhibit characteristic hexagonal structure. In addition, the indexed peaks were also matched with the standard data (ICSD-00-033-1340), which confirmed that samples revealing hexagonal structure consisted of M-type strontium hexaferrites. TGA was performed up to $800^{\circ} \mathrm{C}$ with a heating rate of $20^{\circ} \mathrm{C} / \mathrm{min}$. to determine any carbon related species that may be present in the samples due to reaction of $\mathrm{Sr}^{2+}$ with $\mathrm{CO}_{2}$ which may be available from the atmosphere and/or from the decomposition of citric acid. Figure 2 shows the \%age weight loss for the four samples from room temperature to $800^{\circ} \mathrm{C}$. The curves reveal a good stability and do not indicate any significant weight loss. Hence, it is inferred that no carbon related species are present in the prepared samples and sintering of samples at $800^{\circ} \mathrm{C}$ is sufficient to hinder the formation of $\mathrm{SrCO}_{3}$ enabling the $\mathrm{Sr}^{2+}$ available to stimulate the incorporation of $\mathrm{Sr}^{2+}$ into strontium hexaferrite matrix [11]. Slight increase in the lattice parameters " $a$ " and " $c$ " was observed that led to a minute increase in the unit cell volume $\left(V=0.866 a^{2} c\right)$ as well. The trend might be attributed to the larger ionic
TABLE 1: Values of lattice constants, their axial ratio, unit cell volume $(V)$, crystallite size $(D)$, bulk density $\left(\rho_{b}\right)$, X-ray density $\left(\rho_{x}\right)$, porosity $(P)$, saturation magnetization $\left(M_{s}\right)$, remanence $\left(M_{r}\right)$, $M_{r} / M_{s}$, and coercivity $\left(H_{c}\right)$ at $\mathrm{SrPb}_{x} \mathrm{Fe}_{12-x} \mathrm{O}_{19}(x=0.0,0.1,0.2,0.3$, and 0.4 ).

\begin{tabular}{lccccc}
\hline Parameter & $x=0.0$ & $x=0.1$ & $x=0.2$ & $x=0.3$ & $x=0.4$ \\
\hline$a(\AA)$ & 5.8808 & 5.8856 & 5.8880 & 5.8889 & 5.8911 \\
$c(\AA)$ & 23.2018 & 23.2193 & 23.2297 & 23.2360 & 23.2361 \\
$c / a$ & 3.9453 & 3.9451 & 3.9446 & 3.9457 & 3.9443 \\
$V\left(\mathrm{~nm}^{3}\right)$ & 694.8841 & 696.5439 & 697.3042 & 697.8268 & 698.3515 \\
$D(\mathrm{~nm})$ & 27.8971 & 28.4145 & 28.8917 & 29.9115 & 29.9176 \\
$\rho_{b}\left(\mathrm{~g} / \mathrm{cm}^{3}\right)$ & 2.9124 & 2.9965 & 3.1623 & 3.2817 & 3.2862 \\
$\rho_{x}\left(\mathrm{~g} / \mathrm{cm}^{3}\right)$ & 4.8167 & 4.8266 & 4.8615 & 4.9075 & 4.9080 \\
$P(\%)$ & 39.53 & 37.92 & 34.95 & 33.13 & 33.04 \\
$M_{s}(\mathrm{emu} / \mathrm{g})$ at & 63.22 & 57.79 & 53.16 & 49.65 & 41.62 \\
$300 \mathrm{~K}$ & & & & & \\
$M_{s}(\mathrm{emu} / \mathrm{g})$ at & 70.77 & 63.50 & 60.50 & 53.93 & 48.44 \\
$200 \mathrm{~K}$ & & & & & \\
$M_{r}(\mathrm{emu} / \mathrm{g})$ at & 33.05 & 30.62 & 28.71 & 25.84 & 23.66 \\
$300 \mathrm{~K}$ & & & & & \\
$M_{r}(\mathrm{emu} / \mathrm{g})$ at & 38.20 & 34.81 & 33.65 & 30.96 & 28.84 \\
$200 \mathrm{~K}$ & & & & & \\
$M_{r} / M_{s}$ at $300 \mathrm{~K}$ & 0.52 & 0.53 & 0.54 & 0.55 & 0.57 \\
$M_{r} / M_{s}$ at $200 \mathrm{~K}$ & 0.54 & 0.55 & 0.56 & 0.58 & 0.60 \\
$H_{c}(\mathrm{Oe})$ at $300 \mathrm{~K}$ & 2360 & 3249 & 4360 & 5837 & 6015 \\
$H_{c}(\mathrm{Oe})$ at $200 \mathrm{~K}$ & 3104 & 3471 & 4322 & 4915 & 5282 \\
\hline
\end{tabular}

radius of the substituent, $\mathrm{Pb}^{2+}(0.98 \AA)$ as compared to the host, $\mathrm{Fe}^{3+}(0.49 \AA)$. The crystallite sizes of all the samples evaluated using Scherrer's relation $(D=k \lambda / \beta \cos \theta, k$ is a constant, $\beta$ is full width at half maximum in radians, and $\theta$ is diffraction angle in degrees) were increased slightly as the $\mathrm{Pb}$ concentration was increased in the series. The bulk density $\left(\rho_{b}\right)$ was calculated from the weight and dimensions of the sintered pellets using the relation $\rho_{b}=m / \pi r^{2} h$, where $m$ is the mass, $r$ is the radius, and $h$ is the thickness of the samples. X-ray density $\left(\rho_{x}\right)$ of the samples was calculated using the relation $\rho_{x}=2 M / N_{a} a^{3}$ [12], where $M$ is the molecular weight of the composition, $N_{a}$ is Avogadro's number, and $a$ is the lattice constant. The bulk and X-ray densities were used to calculate the porosity $\left(P=1-\rho_{b} / \rho_{x}\right)$. The values of all these structural parameters have been shown in Table 1 . The results reveal that porosity of the samples was decreased as the $\mathrm{Pb}$ contents were substituted at the Fe sites in the series of the samples. In other words, the grains became more compact and densified with the $\mathrm{Pb}$ substitution which could play a significant role in establishing the structural and magnetic properties.

Figure 3 shows the FTIR spectra of all the prepared samples. In ferrites, the spectroscopically active region lies between $400 \mathrm{~cm}^{-1}$ and $800 \mathrm{~cm}^{-1}$ [13]. In our samples, there were sharp and clear peaks at $600 \mathrm{~cm}^{-1}, 550 \mathrm{~cm}^{-1}$, and $440 \mathrm{~cm}^{-1}$, corresponding to the characteristics peaks of chemical bonds in $\mathrm{SrFe}_{12} \mathrm{O}_{19}$ structure [14]. The peak intensity remained almost the same as the amount that $\mathrm{Pb}$ dopant 


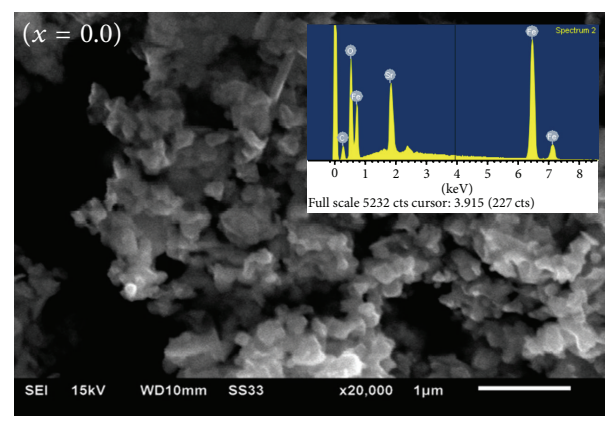

(a)

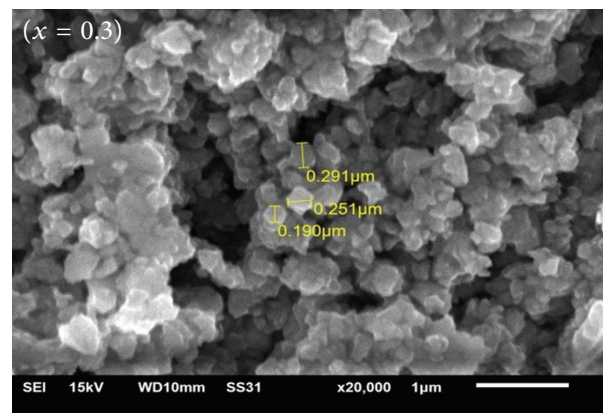

(c)

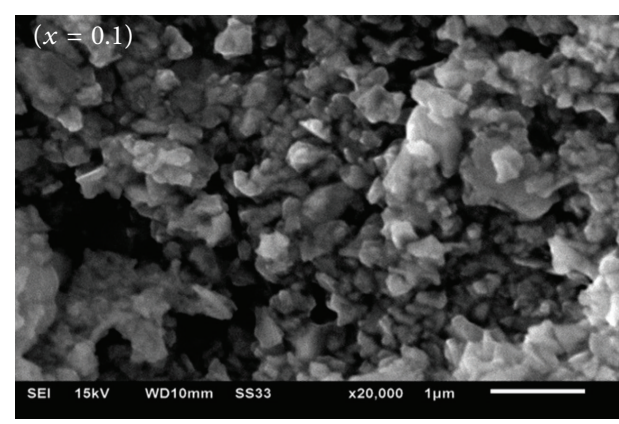

(b)

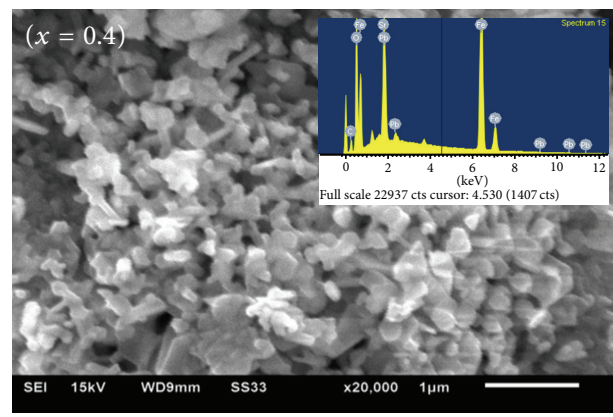

(d)

Figure 4: SEM micrographs of $\mathrm{SrPb}_{x} \mathrm{Fe}_{12-x} \mathrm{O}_{19}(x=0.0,0.1,0.3$, and 0.4$)$ samples.

was increased by in the series, which indicated that $\mathrm{Pb}$ could be successfully substituted in a dilute amount at the Fe sites, without disturbing the stoichiometry of the parent hexagonal $\mathrm{SrFe}_{12} \mathrm{O}_{19}$ structure. With the increase in $\mathrm{Pb}$ contents, the chemical polarization of the internal bonds could be shared in the form of $\mathrm{Fe}-\mathrm{O}-\mathrm{Pb}$ and $\mathrm{Sr}-\mathrm{O}-\mathrm{Pb}$ chemical bonds, resulting in compact structures as that of $\mathrm{SrFe}_{12} \mathrm{O}_{19}$. The peaks at $3421 \mathrm{~cm}^{-1}$ and $1639 \mathrm{~cm}^{-1}$ exhibit the structure and bending bonds of the surface hydrogen group $(-\mathrm{OH})$ earned from the damped environment [15].

Figure 4 shows the microstructural morphology of the samples obtained using a scanning electron microscope. Figure 4(a) reveals the micrograph of pure $\mathrm{SrFe}_{12} \mathrm{O}_{19}$ sample indicating that most of the grains are like platelets having sharp grain boundaries. A close look at this image might provide hindsight of the hexagonal texture of the grains, a characteristic of the hexagonal crystal structure of the $\mathrm{SrFe}_{12} \mathrm{O}_{19}$. With the substitution of $\mathrm{Pb}$ contents at Fe sites, the microstructural morphology of the grains was further refined until at $x=0.3 \mathrm{~Pb}$ contents; well defined hexagonal grains were witnessed which were varying in size ranging from 0.190 to $0.291 \mu \mathrm{m}$. The uniform grain sizes and homogeneous contrast throughout the focused area confirm that the sample consists of single phase ferrite composition. The shape and compatibility of grains play a vital role in determining the structural and magnetic properties of ferrites [16]. The platelet-like hexagonal texture of ferrites has been investigated as a potential candidate for use in microwave absorbing coatings [17]. The elemental composition of the constituents elicited from EDX, shown in the inset of Figures 4(a) and $4(\mathrm{~d})$, confirms the stoichiometric ratio of the elements in the prepared samples and the incorporation of $\mathrm{Pb}$ at Fe sites. The quantitative data of atomic and percentage composition of elements was in close agreement with the dissolved reactants.

Figure 5 shows the magnetic-hysteresis (M-H) loops of the prepared samples obtained at $300 \mathrm{~K}$. Magnetic parameters like saturation magnetization $\left(M_{s}\right)$, remanence $\left(M_{r}\right)$, and coercivity $\left(H_{c}\right)$ were determined from $\mathrm{M}-\mathrm{H}$ loops as listed in Table 1. The $M_{s}$ and $H_{c}$ values as a function of $\mathrm{Pb}$ contents have been plotted in Figure 6. The plots reveal that the substitution of $\mathrm{Pb}$ contents at $\mathrm{A}$-site of Fe changes the magnetic properties of the ferrite samples in a remarkable way. The $M_{s}$ and $M_{r}$ values of the ferrite samples were decreased from 63.22 to $41.62 \mathrm{emu} / \mathrm{g}$ and 33.03 to $23.66 \mathrm{emu} / \mathrm{g}$, respectively, whereas the $H_{c}$ value was increased from 2360 to $6015 \mathrm{Oe}$ with the increase in the $\mathrm{Pb}$ contents. However, the $M_{r} / M_{s}$ ratio was observed to increase from 0.52 to 0.57 in the series, as the decrease in $M_{r}$ value is less prominent as the corresponding decrease in the $M_{s}$ value, making the later samples in the series more effective, as far as energy product is concerned. The value of $M_{s}$ at $x=0$ is in close agreement with a recently reported value [18]. The crystal structure has been understood as a critical factor which decides the magnetic behavior of the material. The crystal structure of $\mathrm{SrFe}_{12} \mathrm{O}_{19}$ has five nonequivalent sublattices with three octahedral (2a, 12k, and 4f), one tetrahedral (4f1), and one trigonal bipyramidal (2b) sites [19]. Among these, three sites (2a, 12k, and $2 \mathrm{~b}$ ) possess upward spin and two sites (4fl and 4f2) spin downward. Hence, net magnetic moment results due to upward spins. When $\mathrm{Pb}$ with a diamagnetic nature is substituted with some of the iron ions, a decrease in the net saturation magnetization is observed which decreases 


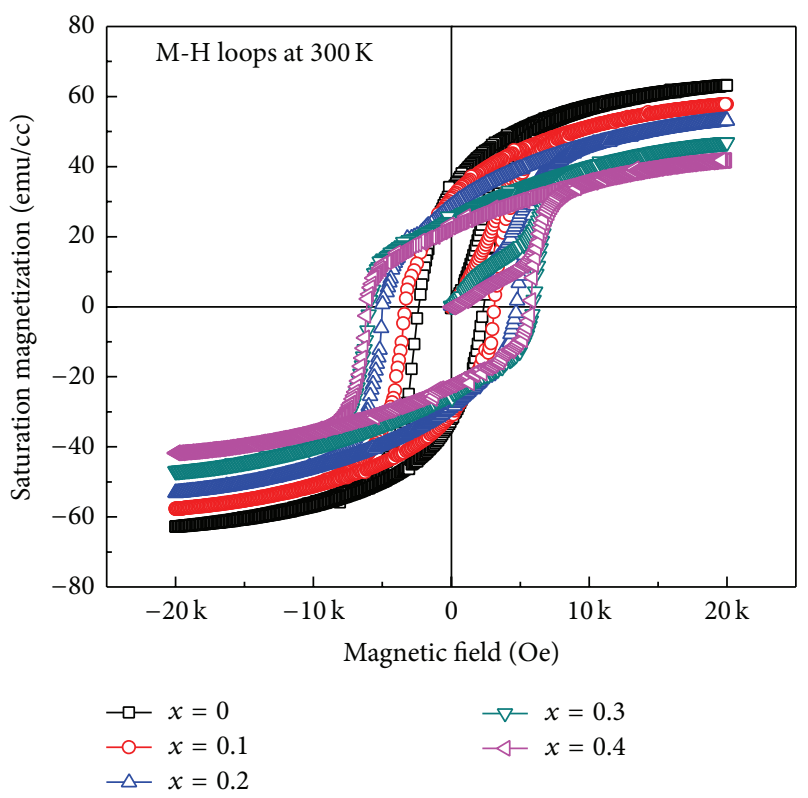

Figure 5: $\mathrm{M}$-H loops of $\mathrm{SrPb}_{x} \mathrm{Fe}_{12-x} \mathrm{O}_{19}(x=0.0,0.1,0.2,0.3$, and 0.4 ) samples at $300 \mathrm{~K}$.

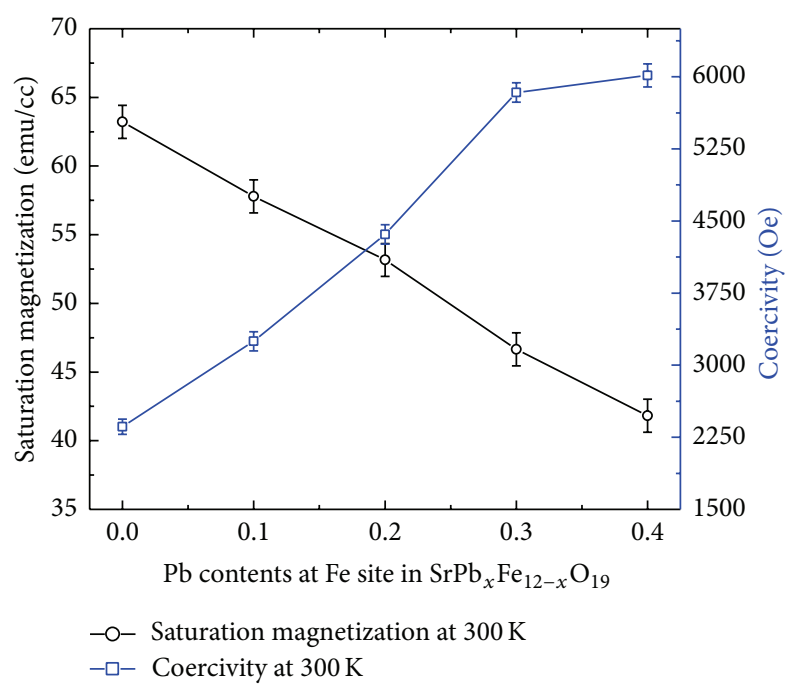

FIgURE 6: $M_{s}$ and $H_{c}$ as a function of $\mathrm{Pb}$ contents at Fe sites in $\mathrm{SrPb}_{x} \mathrm{Fe}_{12-x} \mathrm{O}_{19}$ at $300 \mathrm{~K}$.

further as the $\mathrm{Pb}$ contents are increased up to $x=0.4$. This decrease in $M_{s}$ value could be attributed to the decrease of superexchange interactions among $\mathrm{Fe}_{\mathrm{A}}{ }^{3+}-\mathrm{O}-\mathrm{Fe}_{\mathrm{B}}{ }^{3+}$, as the substituted ions prefer to occupy the octahedral $12 \mathrm{k}$ site which has upward spin [20], followed by $2 \mathrm{a}$ and $4 \mathrm{f} 2$ sites [19]. Each $\mathrm{Fe}^{3+}$ ion possesses a magnetic moment of $5 \mu_{\mathrm{B}}$. Therefore, an M-type molecule of $\mathrm{SrFe}_{12} \mathrm{O}_{19}$ possesses a magnetic moment of $20.6 \mu_{\mathrm{B}}$. The substitution of a diamagnetic ion at a site with spin up reduces the total magnetic moment of the specimen and hence the $M_{s}$ values decrease.

The increase in $H_{c}$ with the increase in $\mathrm{Pb}$ contents may be described on the basis of Stoner-Wohlfarth relation, $H_{c}$

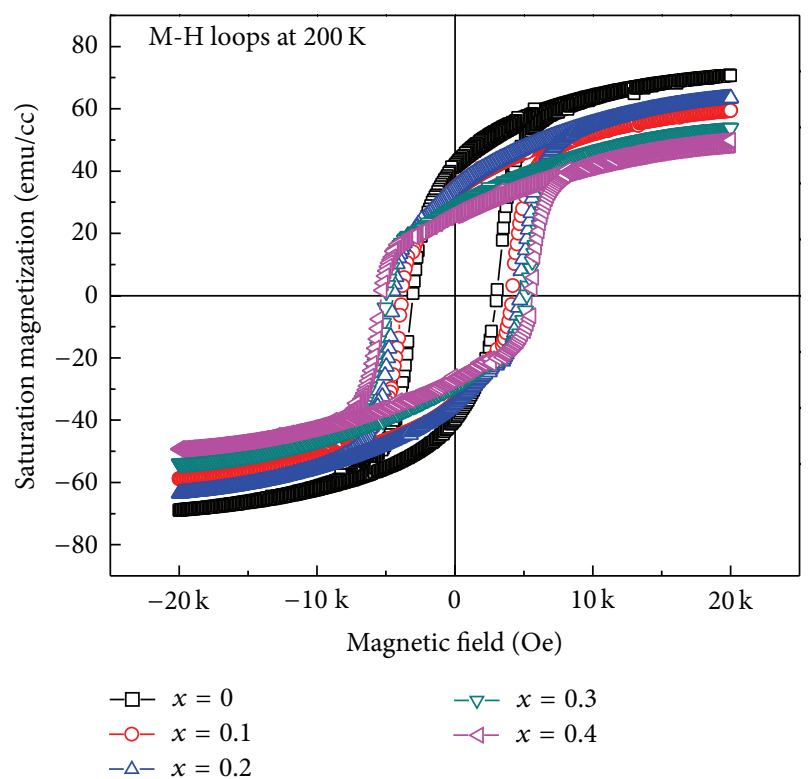

Figure 7: M-H loops of $\mathrm{SrPb}_{x} \mathrm{Fe}_{12-x} \mathrm{O}_{19}(x=0.0,0.1,0.2,0.3$, and 0.4 ) samples at $200 \mathrm{~K}$.

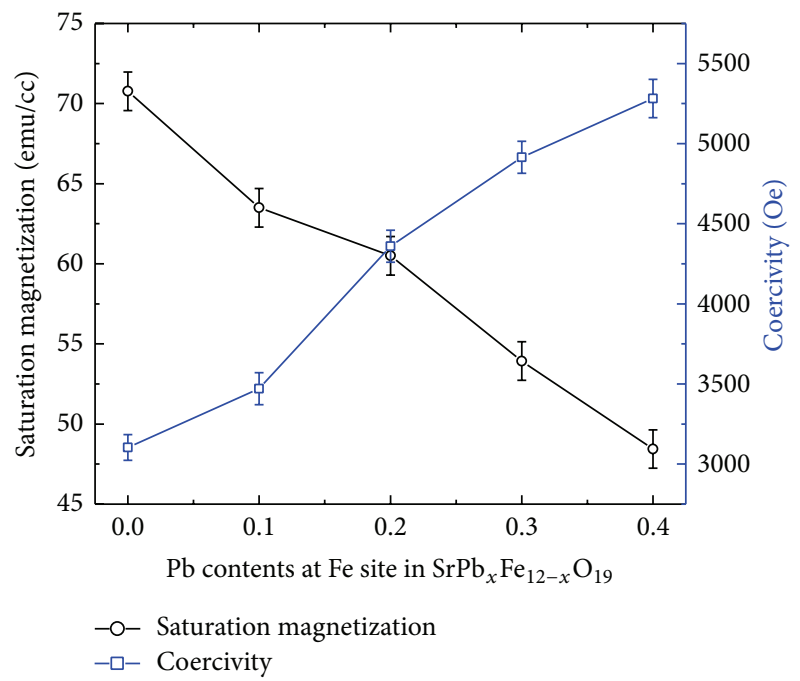

Figure 8: $M_{s}$ and $H_{c}$ as a function of $\mathrm{Pb}$ contents at Fe sites in $\mathrm{SrPb}_{x} \mathrm{Fe}_{12-x} \mathrm{O}_{19}$ at $200 \mathrm{~K}$.

$=2 K / \mu_{0} M_{s}$, where $K$ is magnetocrystalline anisotropy and $\mu_{o}$ is permittivity of free space $\left(=4 \pi \times 10^{-7} \mathrm{H} / \mathrm{m}\right)$. Hence, a decrease in $M_{s}$ and an increase in $K$ [21] are the possible factors for an increased value of $H_{c}$.

Figure 7 shows the $\mathrm{M}-\mathrm{H}$ loops of the samples at $200 \mathrm{~K}$. The $M_{s}$ and $M_{r}$ values of all the samples increased as compared to their corresponding values at $300 \mathrm{~K}$ in the series, with the decrease in temperature, as has been plotted in Figure 8 and listed in Table 1, but decreased with the increase of $\mathrm{Pb}$ contents in the series. The increase in $H_{c}$ as a function of $\mathrm{Pb}$ contents at $200 \mathrm{~K}$ (Figure 7) could also be explained as discussed earlier. The increased values of $M_{s}$ at $200 \mathrm{~K}$ might be described on the basis of Weiss theory of ferromagnetism 
[22]. According to this theory, at low temperatures, the thermal activation energy of the magnetic ions reduces which in turn helps the magnetic moments to align more easily in the applied field direction. Therefore, an overall increase in the magnetic moment and hence in the $M_{s}$ is observed. The increased squareness ratio $\left(M_{r} / M_{s}\right)$ in this case as well favors the use of these materials for the applications where high energy products are desired.

\section{Conclusion}

In this paper, the influence of $\mathrm{Pb}$ doping on the structural and low temperature magnetic behavior of $\mathrm{SrPb}_{x} \mathrm{Fe}_{12-x} \mathrm{O}_{19}(x=$ $0,0.1,0.2,0.3$, and 0.4 ) has been investigated systematically. $\mathrm{X}$-ray diffraction analysis of all the samples revealed the hexagonal phase characteristics of the $\mathrm{SrFe}_{12} \mathrm{O}_{19}$ crystal structure. A slight increase in the lattice constants ( $a$ and $c$ ) and the unit cell volume was attributed to the larger ionic radii of dopant $\mathrm{Pb}$ as compared to the host Fe site. The crystallite size was also increased in the series as the $\mathrm{Pb}$ contents were increased. The porosity was decreased from 39.53 to $33.04 \%$ in the series making the samples more compact to improve the structural and hence the magnetic properties. FTIR spectroscopy confirmed the metal-oxygen bonds formation in the hexagonal structure of the samples. Surface morphology has been described using SEM images and elemental stoichiometric composition has been found using EDX spectroscopy. Saturation magnetization was found to decrease, while coercivity was increased with the increase of $\mathrm{Pb}$ contents in the series at $300 \mathrm{~K}$. When temperature was reduced to $200 \mathrm{~K}$, the saturation magnetization of the relevant samples was increased, credited to the preferred individual spin alignments at low temperature. Remanence was also decreased, but the corresponding effect was less prominent as the $M_{r} / M_{s}$ and consequently the energy product was found to increase, corroborating the use of these ferrite compositions where hard magnetic characteristics are required.

\section{Conflict of Interests}

The authors declare that they have no conflict of interests regarding the publication of this paper.

\section{Acknowledgment}

The authors extend their appreciation to the Deanship of Scientific Research at King Saud University for funding the work through the research group project no. RGP-VPP-106.

\section{References}

[1] Y.-P. Fu and C.-H. Lin, "Fe/Sr ratio effect on magnetic properties of strontium ferrite powders synthesized by microwaveinduced combustion process," Journal of Alloys and Compounds, vol. 386, no. 1-2, pp. 222-227, 2005.

[2] Z. Ullah, S. Atiq, and S. Naseem, "Influence of Pb doping on structural, electrical and magnetic properties of Srhexaferrites," Journal of Alloys and Compounds, vol. 555, pp. 263-267, 2013.
[3] I. V. Zavislyak, M. A. Popov, and G. Srinivasan, "A cut-off millimeter wave resonator technique for mapping magnetic parameters in hexagonal ferrites," Measurement Science and Technology, vol. 20, no. 11, Article ID 115704, 2009.

[4] S. Hussain and A. Maqsood, "Structural and electrical properties of Pb-doped Sr-hexa ferrites," Journal of Alloys and Compounds, vol. 466, no. 1-2, pp. 293-298, 2008.

[5] S.-D. Kim and J.-S. Kim, "Magnetic properties of Sr-ferrites synthesized in molten $(\mathrm{NaCl}+\mathrm{KCl})$ flux," Journal of Magnetism and Magnetic Materials, vol. 307, no. 2, pp. 295-300, 2006.

[6] S. Hussain and A. Maqsood, "Thermal transport properties of silica added $\mathrm{Sr}$-hexa ferrites as a function of temperature," Materials Letters, vol. 62, no. 6-7, pp. 1002-1005, 2008.

[7] L. You, L. Qiao, J. Zheng, M. Jiang, L. Jiang, and J. Sheng, "Magnetic properties of La-Zn substituted Sr-hexaferrites by self-propagation high-temperature synthesis," Journal of Rare Earths, vol. 26, no. 1, pp. 81-84, 2008.

[8] M. J. Iqbal and S. Farooq, "Extraordinary role of Ce-Ni elements on the electrical and magnetic properties of Sr-Ba M-type hexaferrites," Materials Research Bulletin, vol. 44, no. 11, pp. 2050-2055, 2009.

[9] C. M. Fang, F. Kools, R. Metselaar, G. De With, and R. A. De Groot, "Magnetic and electronic properties of strontium hexaferrite $\mathrm{SrFe}_{12} \mathrm{O}_{19}$ from first-principles calculations," Journal of Physics Condensed Matter, vol. 15, no. 36, pp. 6229-6237, 2003.

[10] B. D. Cullity, Elements of X-Ray Diffraction, Addison-Wesley, 2nd edition, 1978.

[11] R. M. Garcia, E. R. Ruiz, and E. E. Rams, "Structural characterization of low temperature synthesized $\mathrm{SrFe}_{12} \mathrm{O}_{19}$ " Materials Letters, vol. 50, no. 2-3, pp. 183-187, 2001.

[12] J. Smit and H. P. J. Wijn, Ferrites, John Wiley \& Sons, New York, NY, USA, 1959.

[13] X. Yang, Q. Li, J. Zhao, B. Li, and Y. Wang, "Preparation and magnetic properties of controllable-morphologies nano$\mathrm{SrFe}_{12} \mathrm{O}_{19}$ particles prepared by sol-gel self-propagation synthesis," Journal of Alloys and Compounds, vol. 475, no. 1-2, pp. 312315, 2009.

[14] T. Xie, L. Xu, and C. Liu, "Synthesis and properties of composite magnetic material $\mathrm{SrCo}_{\mathrm{x}} \mathrm{Fe}_{12-\mathrm{x}} \mathrm{O}_{19}(\mathrm{x}=0-0.3)$," Powder Technology, vol. 232, pp. 87-92, 2012.

[15] S. Kong, P. Zhang, X. Wen et al., "Influence of surface modification of $\mathrm{SrFe}_{12} \mathrm{O}_{19}$ particles with oleic acid on magnetic microsphere preparation," Particuology, vol. 6, no. 3, pp. 185190, 2008.

[16] M. Ahmad, R. Grossinger, M. Kriegisch, F. Kubel, and M. U. Rana, "Characterization of Sr-substituted W-type hexagonal ferrites synthesized by sol-gel autocombustion method," Journal of Magnetism and Magnetic Materials, vol. 332, pp. 137-145, 2013.

[17] J. Xu, H. Zou, H. Li, G. Li, S. Gan, and G. Hong, "Influence of $\mathrm{Nd} 3+$ substitution on the microstructure and electromagnetic properties of barium W-type hexaferrite," Journal of Alloys and Compounds, vol. 490, no. 1-2, pp. 552-556, 2010.

[18] F. S. Jesus, A. M. Bolarin-Miro, C. A. Cortes-Escobedo, R. Valenzuela, and S. Ammar, "Mechanosynthesis, crystal structure and magnetic characterization of M-type $\mathrm{SrFe}_{12} \mathrm{O}_{19}$," Ceramics International, vol. 40, no. 3, pp. 4033-4038, 2014.

[19] S. Singhal, T. Namgyal, J. Singh, K. Chandra, and S. Bansal, "A comparative study on the magnetic properties of $\mathrm{MFe}_{12} \mathrm{O}_{19}$ and $\mathrm{MAlFe}_{11} \mathrm{O}_{19}(\mathrm{M}=\mathrm{Sr}, \mathrm{Ba}$ and $\mathrm{Pb})$ hexaferrites with different morphologies," Ceramics International, vol. 37, no. 6, pp. 18331837, 2011. 
[20] M. J. Iqbal, M. N. Ashiq, P. Hernandez-Gomez, and J. M. Munoz, "Synthesis, physical, magnetic and electrical properties of Al-Ga substituted co-precipitated nanocrystalline strontium hexaferrite," Journal of Magnetism and Magnetic Materials, vol. 320, no. 6, pp. 881-886, 2008.

[21] D. Y. Chen, Y. Y. Meng, D. C. Zeng, Z. W. Liu, H. Y. Yu, and X. C. Zhong, "CTAB-assisted low-temperature synthesis of $\mathrm{SrFe}_{12} \mathrm{O}_{19}$ ultrathin hexagonal platelets and its formation mechanism," Materials Letters, vol. 76, pp. 84-86, 2012.

[22] P. Weiss, "L’hypothèse du champ moléculaire et la propriété ferromagnétique," Journal of Physics, Theory Applications, vol. 6, no. 4, pp. 661-690, 1907. 

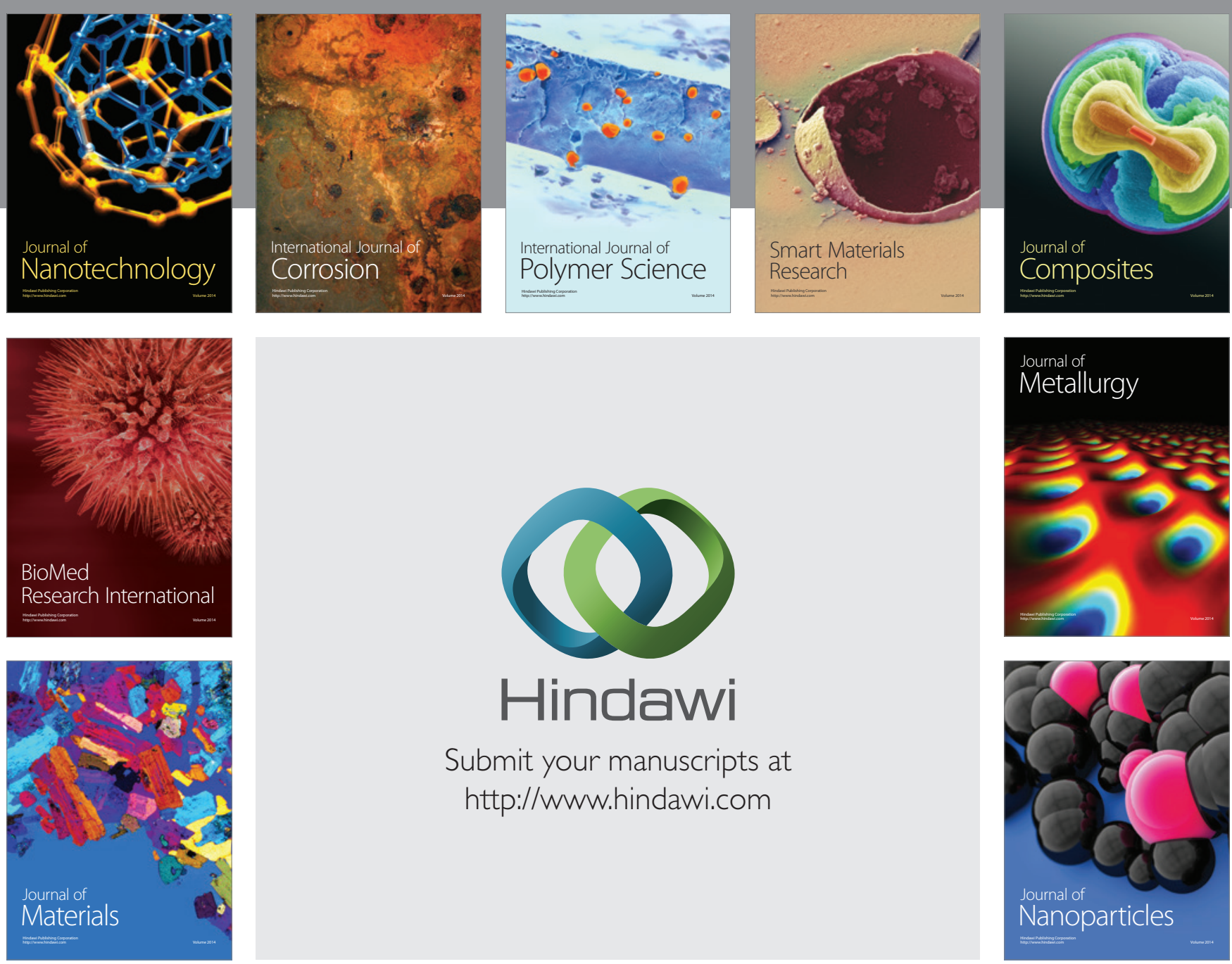

Submit your manuscripts at http://www.hindawi.com
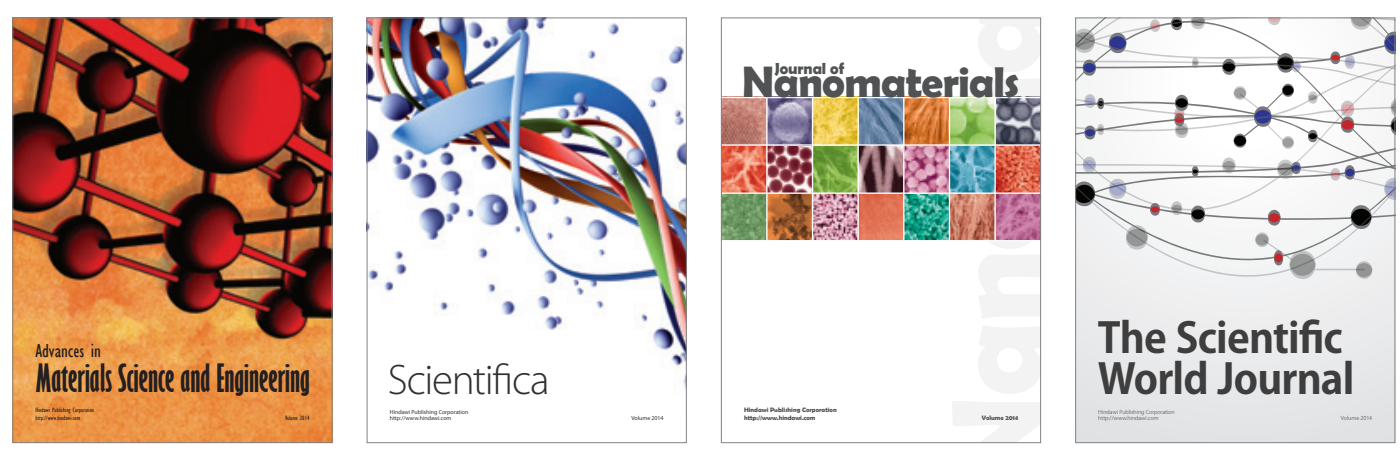

\section{The Scientific World Journal}
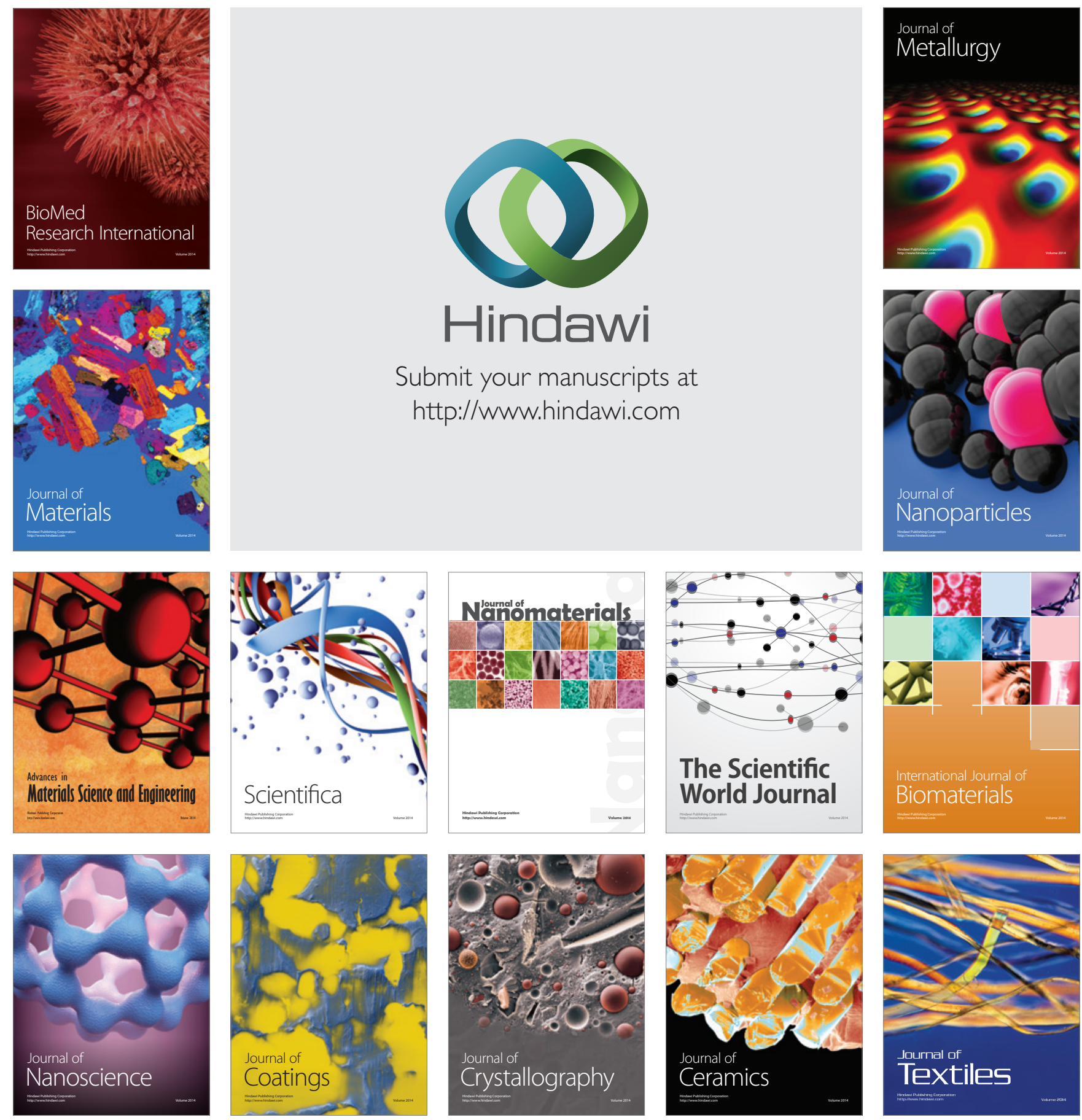